\begin{tabular}{|l|}
\hline 014 - 015 \\
Noticias \\
y comentarios \\
PH44 - Julio 2003 \\
\hline
\end{tabular}

Asimismo se propone la posibilidad de reproducir una obra con el fin de anunciar su exposición publica o para promocionar el acto, hecho que no se puede considerar un daño por los titulares de derechos, sino una ayuda a la difusión de sus creaciones.

Se propone que la aplicación de los límites afecten únicamente a los derechos y modalidades de explotación, y que las utilizaciones al amparo de los limites no conlleven compensación económica a favor del autor. Por último, se con- sidera de suma importancia la figura de una Comisión de Propiedad Intelectual que pueda mediar, en los casos de conflictos, entre las entidades de gestión y las bibliotecas y centros similares, como usuarios del repertorio, y sus asociaciones.

Isabel Ortega Vaquero

Centro de Documentación del IAPH
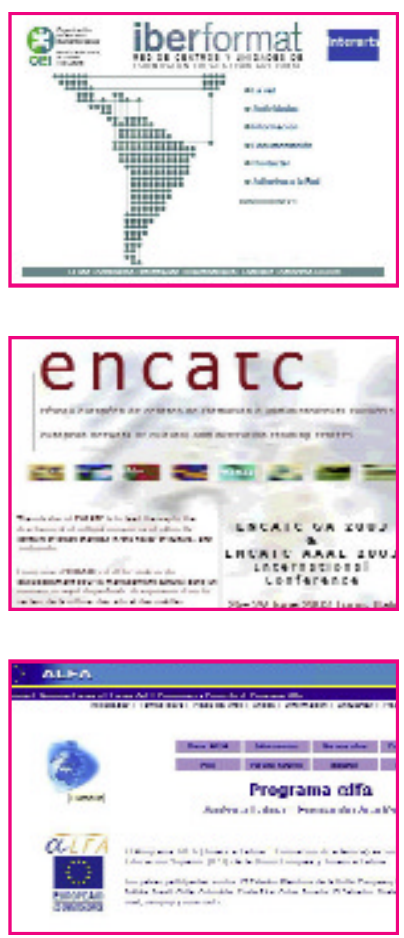

\title{
Redes de formación en gestión cultural
}

A partir de una definición de red no sólo física sino más bien entendida como la trama que forman varias personas o instituciones que solicitan, proporcionan e intercambian experiencias e informaciones a través de sistemas de comunicación, destacamos algunas de las más importantes redes que se dedican a la formación en el sector cultural, y otras, que aunque no sean redes propiamente, se deben resaltar por la abundante información que aportan y los enlaces de interés con que cuentan.

La Red de Centros y Unidades de Formación en Gestión Cultural -Red Iberformat (uww.iberformat.net)es la más destacada en lengua española. Surge de la iniciativa de la Organización de Estados Iberoamericanos (OEI) y de la Fundación Interarts a fines de 2001. Entre los objetivos primordiales que se plantea Iberformat destacan:

> crear una red de centros de formación y unidades de capacitación en gestión cultural;

> establecer programas de formación específicos; > introducir una perspectiva internacional en los contenidos para una mayor presencia de las culturas de Iberoamérica en un mundo globalizado; > facilitar la transferencia de nuevas reflexiones; > establecer un banco de recursos formativos con materiales on-line.

Iberformat también aporta información mediante la Base de datos sobre centros y unidades de formación en gestión cultural en Iberoamérica y a través de los enlaces que tiene con otras redes de formación y redes culturales y artísticas.

La Red Europea de Centros de Formación de Administradores Culturales -ENCATC (www.encatc.org)tiene como objetivo principal orientar para que la gestión cultural evolucione dentro del contexto de grandes cambios en los campos de la cultura, las artes y los medios de comunicación. Esta Red cuenta con importantes expertos europeos, conferenciantes y especialistas en administración y gestión cultural, en políticas culturales y en finanzas. Desde su creación, en 1992, ENCATC coopera frecuentemente con el Consejo de Europa y también ha establecido relaciones de trabajo con otras instituciones europeas e internacionales.
Aunque no podemos considerarla una red de formación como tal, es interesante hacer un comentario sobre la Asociación de Educadores de Administración de Artes -AAAE (www.artsnet.org/aaae)organización internacional sin ánimo de lucro con sede en los Estados Unidos, cuya misión es presentar los programas de estudio en Administración de las Artes abarcando la gestión en diferentes aspectos culturales que se llevan a cabo en titulaciones universitarias y posgrados. Fundada en 1975, la AAAE fue creada para ofrecer un foro de comunicación entre sus miembros y defender la formación para la gestión y administración de artes.

\section{Enlaces de interés}

La web de la Organización de Estados Iberoamericanos (www.oei.es/superiorenla.htm) contiene un amplísimo listado de enlaces de interés relacionados con la Educación Superior. Asimismo, el Programa ALBAN de Becas (http://europa.eu.int/comm/ europeaid/projects/albanindex_es.htm), convocado por la Comisión Europea para la promoción de la cooperación en materia de educación superior entre la Unión Europea y América Latina, cubre estudios para posgraduados y formación especializada para profesionales latinoamericanos en instituciones o centros de la Unión Europea.

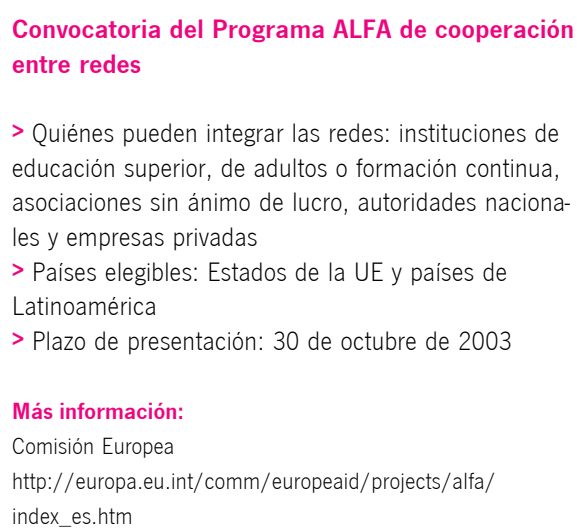

Convocatoria del Programa ALFA de cooperación entre redes

> Quiénes pueden integrar las redes: instituciones de educación superior, de adultos o formación continua, asociaciones sin ánimo de lucro, autoridades nacionales y empresas privadas

> Paises elegibles: Estados de la UE y paises de Latinoamérica

> Plazo de presentación: 30 de octubre de 2003

Más información:

Comisión Europea

http://europa.eu.int/comm/europeaid/projects/alfa/ index_es.htm

Julio Rodriguez Bisquert

Dpto. Formación y Comunicación del IAPH 